\title{
EMPREENDEDORISMO NA ENFERMAGEM: UMA NECESSIDADE PARA INOVAÇÕES NO CUIDADO EM SAÚDE E VISIBILIDADE PROFISSIONAL
}

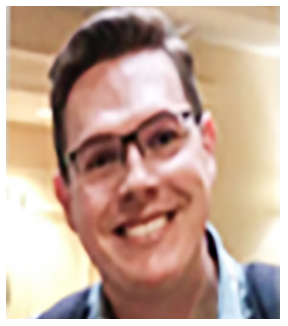

José Luis Guedes dos Santos

Professor Adjunto do Departamento de Enfermagem da Universidade Federal de Santa Catarina (UFSC), Florianópolis, SC, Brasil. Editor Associado da Revista Enfermagem em Foco. ORCID: https://orcid.org/0000-0003-3186-8286 Email: jose.santos@ufsc.br

O desenvolvimento de competências para a inserção no mercado de trabalho e o atendimento das necessidades da sociedade é cada vez mais importante para os profissionais de enfermagem. Esse é um processo que deve ocorrer desde o momento da formação visando à construção de um perfil empreendedor, que envolve características como autoconfiança, espírito crítico, proatividade, criatividade, disposição para a inovação e capacidade de negociação, entre outras competências.

De modo geral, o empreendedorismo pode ser definido como o ato de fazer algo novo e diferente, a partir da identificação de necessidades não atendidas e proposição de soluções inovadoras e criativas. Isso pode acontecer dentro de um nicho de mercado, o que caracteriza o empreendedorismo empresarial; enquanto colaborador de uma empresa, o que se configura como intraeempreendedorismo; ou em prol da transformação social, sendo denominado de empreendedorismo social.(1) Assim, diferente da visão predominante no senso comum, o empreendedorismo não está associado somente ao desenvolvimento de um negócio com finalidade lucrativa.

Na Enfermagem, o empreendedorismo social ocorre quando o enfermeiro atua como agente de mudanças e transformações positivas para pacientes e famílias inseridos em sua comunidade. $\mathrm{O}$ intraempreendedorismo remete à atuação do enfermeiro como um agente de mudança e inovação em organizações públicas e privadas, nas quais atuam como empregados. O empreendedorismo empresarial caracteriza-se pela prática autônoma de enfermeiros, como, por exemplo, em consultórios no atendimento de pacientes com feridas, cuidado domiciliar, assistência privada nos serviços de obstetrícia e puerpério materno. ${ }^{(1)}$ No contexto

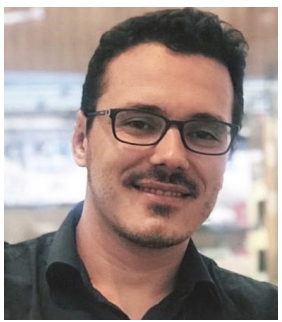

Alisson Fernandes Bolina Professor Adjunto do Departamento de Enfermagem da Faculdade de Ciências da Saúde da Universidade de Brasilia (UnB), Brasilia, DF, Brasil. ORCID: https://orcid.org/0000-0002-1364-0176 Email: alissonbolina@unb.br

do empreendedorismo empresarial, é importante pontuar que, no Brasil, o funcionamento dos consultórios e clínicas de Enfermagem é regulamentado pelo Conselho Federal de Enfermagem por meio da Resolução no. 0568/2018(2), o que representa um avanço e incentivo para a prática autônoma do enfermeiro.

Diante dessas diferentes tipologias, considera-se que o empreendedorismo não é apenas uma competência importante para a busca de uma prática autônoma, mas também uma característica que potencializa a prática dos profissionais de enfermagem no cuidado às pessoas e coletividades. A Enfermagem tradiciononalmente tem potencial para o desenvolvimento de inovações e transformações no processo de cuidar em saúde. A própria história da Enfermagem ilustra esse espírito empreendedor a partir da figura de Florence Nightingale.

No século XIX, pela sua atuação pioneira da Guerra da Criméia e fundação da Escola de Enfermagem no Hospital Saint Thomas na Inglaterra, ela deu início às bases científicas da profissão e tornou-se a precursora da Enfermagem Moderna. Esses feitos tornam-na também um grande exemplo de uma enfermeira empreendedora.

Apesar disso, o empreendedorismo ainda está longe de ser um tema frequente nas discussões e rodas de conversa no contexto da prática, do ensino e da pesquisa em enfermagem. Portanto, torna-se necessário divulgar e desmistificar o tema entre os profissionais de enfermagem a fim de instigá-los na (re)criação e busca por inovação nos processos que envolvem o trabalho em saúde, bem como para o desenvolvimento e implementação de tecnologias de cuidado pautadas nas necessidades sociais e institucionais. ${ }^{(3)}$ 
No âmbito da graduação, as Empresas Júniores (EJ) representam uma estratégia criativa de ensino-aprendizado para formação empreendedora, em que os alunos são instigados a construírem e conquistarem novos campos de atuação profissional. ${ }^{4} \mathrm{~A} E J$ é associação sem fins lucrativos de cunho educacional, formadas e geridas apenas por alunos da graduação, que ofertam serviços de qualidade sob orientação de professores/consultores e com custo competitivo, tornando-se mais atrativas economicamente. De acordo com dados da Brasil Júnior, há aproximadamente, 900 EJ no País. Porém, apenas três EJ federadas no âmbito nacional são da área da Enfermagem. ${ }^{5}$ Esse dado indica a necessidade de investimentos em âmbito universitário para a formação de enfermeiros empreendedores, seja por meio de EJ ou outras estratégias.

Uma formação empreendedora pode contribuir na oferta de respostas às necessidades sociais e de cuidado em saúde da população, sobretudo na criação de práticas inovadoras necessárias frente as constantes transformações econômicas, sociais, políticas e ambientais. Ademais, o empreendedorismo como estratégia para profissão enquanto prática social, pode modificar o status quo, isto é, lutar pela melhoria das condições de trabalho e para a consolidação dos princípios norteadores do Sistema Único de Saúde nos serviços de saúde. ${ }^{6}$ Assim, o empreendedorismo na enfermagem representa uma possibilidade para inovações no cuidado em saúde e, por conseguinte, ampliação da visibilidade da profissão no sistema de saúde e na sociedade de forma mais ampla também.

A divulgação da produção do conhecimento e das práticas desenvolvidas pela Enfermagem também pode contribuir para o fortalecimento e maior visibilidade do seu potencial empreendedor. Dessa forma, a partir da publicação de artigos originais, artigos de revisão, artigos de opinião, reflexão e relato de experiência, esta edição da Revista Enfermagem em Foco contém uma variedade de inovações desenvolvidas por enfermeiros no cuidado em saúde nos mais diversos cenários de prática e regiões do Brasil.

O empreendedorismo não é apenas uma competência importante para a busca de uma prática autônoma, mas também uma caracteristica que potencializa a prática dos profissionais de enfermagem no cuidado às pessoas e coletividades. Por meio do empreendedorismo empresarial, intraempreendedorismo e empreendedorismo social o enfermeiro pode contribuir para inovações no cuidado em saúde e, por conseguinte, ampliar a visibilidade da profissão.

Descritores: Mercado de Trabalho; Contrato de Risco; Educação em Enfermagem; Papel do Profissional de Enfermagem.

\section{ENTREPRENEURSHIP IN NURSING: A NEED FOR INNOVATIONS IN HEALTH CARE AND PROFESSIONAL VISIBILITY}

Descriptors: Labor Marketing; Risk Contract; Education, Nursing; Nurse's Role.

\section{EMPRENDIMIENTO EN ENFERMERİA: NECESIDAD DE INNOVACIONES EN ATENCIÓN MÉDICA Y VISIBILIDAD PROFESIONAL}

Descriptores: Mercado de Trabajo; Acuerdo de Riesgo; Educácion em Enfermería; Rol de la Enfermera.

1. Copelli FHS, Erdmann AL, Santos JLG. Entrepreneurship in Nursing: an integrative literature review. Rev Bras Enferm. 2019;72(Suppl 1):289-98. DOI: http://dx.doi.org/10.1590/0034-7167-2017-0523

2. Conselho Federal de Enfermagem (Cofen). Resolução COFEN no 568, de 9 de fevereiro de 2018. Aprova o Regulamento dos Consultórios de Enfermagem e Clínicas de Enfermagem. Diário Oficial da União 2018; 20 fev.

3. Backes DS, Obem MK, Pereira SB, Gomes CA, Backes MTS, Erdmann AL. Learning Incubator: an instrument to foster entrepreneurship in Nursing. Rev Bras Enferm. 2015;68(6):794-8. DOI: http://dx.doi.org/10.1590/0034-7167.2015680615i

4. Spagnol CA, Bastos JM. Empresa Júnior: espaço criativo e empreendedor de ensino-aprendizagem na Enfermagem. Enferm. Foco. 2015 [Acesso 18 dez 2019]:4(3,4):164-6. Disponivel em: http://revista.cofen.gov.br/index.php/enfermagem/article/view/541

5. Bolina AF. A enfermagem no contexto sociopolítico e econômico contemporâneo: estímulo ao empreendedorismo privado e/ou fortalecimento do empreendedorismo social? Rev Enferm Atenção Saúde 2019 [Acesso 13 jun 2020]: 8(1):1-3. Disponivel em: http://seer.uftm.edu.br/revistaeletronica/ index.php/enfer/article/view/3898

6. Confederação Brasileira de Empresas Juniores. Relatório Censo \& Identidade [Internet]. Brasilia: Brasil Junior; 2018 [Acesso 18 dez 2019$]$. Disponivel em: https://www.brasiljunior.org.br/conheca-o-mej 